\title{
The Uses of Penicillin and Streptomycin
}




\section{The Uses of Penicillin and Streptomycin}

by

\section{Chester Scott Keefer, M.D. \\ Wade Professor of Medicine, Boston University School of Medicine}

Director of Evans Memorial and Physician-in-Chief of the Massachusetts Memorial Hospitals

Porter Lectures, Series 15

University of Kansas Press, Lawrence, Kansas, 1949 
Copyright, 1949, By the University OF KANSAS Press

All Rights Reserved

PRINTED IN THE U.S.A. BY THE UNIVERSITY OF RANSAS PRESS

IAWRENCE, RANSAS 


\section{Contents}

I.

Penicillin in Medical and Surgical Practice ......... 1

II.

Streptomycin in the Treatment of Infections ...... 23

III.

Antibacterial Agents from Microbes

INDEX 


\section{Preface}

The Uses of Penicillin and Streptomycin consists of the three Porter Lectures delivered under the auspices of the University of Kansas School of Medicine. I am informed that Dr. J. L. Porter came to Kansas from Ohio in 1868, just two years after the founding of the University. After graduating from Rush Medical College in 1881, he returned to Kansas, where he practiced medicine until his death. During his lifetime, Dr. Porter had an opportunity to follow the rapid growth and development of medical science in this country. His interest in scholarship and in medical research led to his establishing the lectureship which bears his name.

I wish to express to the Committee on the Porter Lectures my sincere appreciation for the honor of giving them.

Chester S. Keefer, M. D.

Boston, 1949 


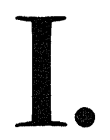




\section{I.}

\section{Penicillin in Medical and Surgical Practice}

Doubtless no therapeutic agent has caused more discussion than penicillin. No other antiinfective agent has been used so widely with such successful results in so many different diseases. It was only six years ago that the first patient was treated adequately with penicillin in the United States. It is impossible to assess completely the benefits that have flowed from the discovery and development of penicillin. At the beginning of our discussion it is well to say something about the dosage forms of penicillin that are available for clinical use.

DOSAGE FORMS FOR USE IN TREATMENT OF SYSTEMIC INFECTIONS

Amorphous Penicillin. Amorphous penicillin is now used less and less, because it is a mixture of penicillins. That is to say, it contains penicillin G-K-F. Penicillin G is the product about which we have the greatest amount of information and which we know is highly effective. In spite of the fact that many samples of amorphous penicillin were found to contain at least 85 per cent penicillin $G$, it became unpopular as an agent for the treatment of all infections because it was shown that penicillin $\mathrm{K}$ was 


\section{PENICILLIN}

relatively ineffective in the treatment of experimental syphilis, and less effective than penicillin $G$ in the treatment of experimental streptococcic and pneumococcic infection in mice. At present, there are some preparations of amorphous calcium penicillin in penicillin in oil and wax or amorphous aluminum penicillin in oil, available for use, but very little amorphous penicillin is now available for use in aqueous preparations.

Crystalline Penicillin G. This is the most widely used preparation parenterally and orally. The crystals are dispensed in aqueous solutions, or suspended in peanut oil and wax, for parenteral use. They are combined with buffers in tablets for oral use, and combined with ointments for topical use.

Salts of Penicillin. There are two commonly used salts of penicillin, the sodium and the potassium. They are both soluble and active, and there is no choice between the two salts in so far as therapeutic results are concerned. Recently a new salt has been prepared, procaine salt of benzyl penicillin. This salt is soluble in 0.7 per cent solution and contains approximately 50 per cent procaine. It is suspended in sesame oil and is used intramuscularly. It is absorbed slowly, so that in many patients penicillin is found in the blood for as long as thirty-six to forty-eight hours following a single injection of 300,000 units. Also, aluminum stearate has been used as an agent along with peanut oil to delay the absorption of potassium penicillin $\mathrm{G}$.

Oral Penicillin. The ideal way to give any drug is by mouth. It is now established that penicillin can be ab- 
sorbed from the gastrointestinal tract, but given by mouth about five times as much penicillin is required to obtain plasma concentrations comparable to those obtained when penicillin is given by the intramuscular route. That penicillin is effective by the oral route has been repeatedly demonstrated by many observers. One of the drawbacks to its more widespread use has been its cost.

Aerosol Penicillin. Crystalline penicillin G, dissolved in physiological salt solution, is used as an aerosol for the treatment of bronchopulmonary disease or chronic paranasal sinusitis. Two hundred thousand to $1,000,000$ units may be used daily for aerosol treatment. The solutions are passed through a DeVilbiss No. 40 or a vaponephrin nebulizer, a hand bulb or a constant pressure of oxygen flowing at the rate of 6 liters a minute being used.

Penicillin in Ointments. Ointments for the local or topical application of penicillin are available for use in the conjunctivae or on the skin. They are stable and useful for the treatment of infections locally. They should be used sparingly and for a brief period of time, since sensitization may arise following the use of penicillin in this way much more often than when it is taken orally or given parenterally.

\section{DOSAGE}

An adequate dose of penicillin might be defined as that amount that will cure the patient with a susceptible infection, in the shortest period of time, and eliminate the infecting organisms from the body. Since there are so many variables in the treatment of any specific infec- 


\section{PENICILLIN}

tion in man it is extremely difficult to make any categorical rules concerning dosage in a given infection. It is important, nevertheless, to develop the best methods of treatment with penicillin so that optimum results may be obtained with the least discomfort and expense to the patient. One of the greatest difficulties that face us in attempting to assess dosage of penicillin is the fact that it is a nontoxic drug. That is to say, very large amounts of penicillin can be given for long periods of time without producing any signs of intoxication. When any drug is nontoxic, it is difficult to determine the minimumeffect dose, because the temptation is great to give larger amounts of the drug than are necessary for producing a favorable clinical result.

Other factors of importance in dosage are the type of infection, and its location. Everyone knows that penicillin is an agent that inhibits the growth of a wide variety of bacteria, but different species of bacteria vary enormously in their resistance to the action of the drug. In fact, different strains of organisms within a species will often vary in their susceptibility to penicillin. All these factors make it difficult to define the minimum effective dose for each infection. In spite of the difficulties involved, it is well to review some of the information concerned with (1) the mode of action of penicillin, (2) the effective plasma concentrations that inhibit the growth of organisms, and (3) the time-dose relationships.

Mechanism of Action of Penicillin. Speaking broadly, penicillin is both bacteriostatic and bactericidal. The destructive power of penicillin in vitro and probably in 


\section{PENICILLIN}

vivo is greatest during the period when the bacteria are multiplying rapidly. It has been demonstrated in vitro that the greatest number of organisms are killed during the first five to eight hours after exposure to penicillin. The organisms that survive this initial period may not be killed for twenty-four to thirty-six hours in spite of the fact that they are exposed to the continuing action of penicillin. When the organisms that survive the five- or eight-hour period are removed from the environment of penicillin and re-inoculated into fresh broth without penicillin, it is found that their lag period is slightly prolonged, but once they start to reproduce, they are highly susceptible once more to the action of penicillin. From such in vitro observations, it has been suggested that penicillin must be maintained at a minimal effective concentration for a sufficiently long period of time, so that all organisms are destroyed and their reproduction prevented.

It has been suggested further that recovery from a given infection in man will occur once the minimum concentration of penicillin is maintained in the blood and tissues for a sufficient period of time to kill off large numbers of organisms and to prevent their reproduction. When the minimum effective concentration necessary to produce a remission is not maintained for a much longer period of time than that necessary to reduce the total number of organisms, then relapse will occur. Both the concentration of penicillin and the time of exposure of the organisms are important. It would appear that the total time organisms are exposed to minimum effective 


\section{PENICILLIN}

concentrations of penicillin is more important than the exposure of organisms to high concentrations of penicillin for a short period of time alternating with penicillinfree periods. There are good reasons for believing that the minimum effective level in man need not be continuous through the 24 -hour period in order to bring about recovery from infection, but the minimum effective concentration must be maintained for a sufficiently long period of time for the organisms to be destroyed or prevented from entering a phase of active growth once again. This statement naturally raises two questions: (1) What is a minimum effective level and (2) what is the timeinterval between intramuscular injections in man that is required in order to obtain the optimum results?

Minimum Effective Plasma and Tissue Concentrations of Penicillin. Let us now turn our attention briefly to the question of the minimum effective level of penicillin in the blood and tissues. Theoretically this minimum effective level would be the amount that would cause complete inhibition of the growth of organisms and their destruction. The determination of minimum effective levels of penicillin that will kill organisms in the test tube is much easier than the determination of the minimal effective plasma and tissue concentrations in the human body. Moreover, it is widely recognized that one cannot in every instance transfer in vitro activity to in vivo conditions with penicillin. Nevertheless, the sensitivity of a given organism to penicillin gives one a rough approximation of the effective concentrations of penicillin that will be needed to inhibit the growth of organisms at the 
site of the infection. The plasma concentrations of penicillin can be determined readily. The concentration of penicillin in the tissues may be more difficult to ascertain. We know, however, that considerable differences exist between plasma and tissue concentrations.

In general, it has been shown that the concentration of penicillin which can be delivered to the tissues (except in the case of spinal fluid, organized thromboses, abscesses) is between 10 and 50 per cent of that in the plasma. Therefore, for any desired concentration in the tissues, it would be well to maintain a concentration of penicillin two to ten times that in the circulating blood. As an example, one could say that if the sensitivity of an organism in vitro was .02 unit per milliliter, then it would be desirable to maintain a plasma concentration of .04 or .2 unit per milliliter in order for the tissue concentration to be approximately .02 unit. While this is perhaps somewhat theoretical, it as least gives one a rough guide to the minimum effective level of penicillin in blood and tissues.

It can be said, then, that the minimum effective plasma and tissue concentration should be at least two to ten times the amount of penicillin that will produce a bactericidal effect against the organism in vitro.

From this discussion of dosage so far, you probably have gathered that the therapeutic activity of a given dose of penicillin will depend upon the amount that is given and the total length of time that penicillin remains at the maximum bactericidal level in the blood and tissues plus the time required for the organisms to recover 


\section{PENICILLIN}

from penicillin and begin multiplication. We know from experience that it is unnecessary to maintain the concentration of penicillin in the blood and tissues continuously at the maximum bactericidal level in order to attain recovery. But the truth of the matter is that the optimum time-dose relationships have not been worked out for all infections, and we do not know whether the present-day results can be improved by changing time-dose relationships or not.

Time-Dose Relationships. There are two points of view concerning time-dose schedules of penicillin: (1) intermittent treatment, so spaced that there are periods of effective plasma concentrations separated by penicillin-free intervals; (2) intermittent or continuous injections of penicillin that will maintain an effective bactericidal plasma concentration for a sufficient period of time to inhibit completely the growth of organisms, plus the time required for the organisms to recover from the drug and effectively resume multiplication. In other words, one point of view is that penicillin should be present in the blood continuously, or at least for prolonged periods of time, and the other view is that penicillin need be present in the blood only intermittently: The difficulty in deciding how often and how much penicillin should be given resolves itself into determining what an effective plasma concentration should be and how long a period may elapse between injections before bacteria will begin to grow once again and cause relapse. Only experience and experiments with various infections can provide the answers for all infections. 
I. PENICILLIN

In our own clinic, Dr. Weinstein has demonstrated that following the use of 100,000 units of penicillin every eight hours in children, penicillin is found in the blood for only two hours after injection, i.e., six hours out of the 24-hour period; and that streptococci disappear from the local lesions promptly within twenty-four to forty-eight hours. Moreover, following the use of 300,000 units of penicillin by mouth every eight hours, similar good results were obtained, but penicillin was detected in the blood for a longer period of time, i.e., for six hours after each injection.

It seems plain, therefore, that in the treatment of hemolytic streptococcic infections in children periods of effective concentrations separated by penicillin-free intervals are in fact as effective as continuously maintained levels.

In gonococcic infections, we know that 98 per cent of patients can be cured with a single injection of 300,000 units of penicillin in oil and wax or with 50,000 units given in aqueous solution every three hours for three doses (total dosage, 150,000 units). We have some evidence that as little as 17,500 units of procaine penicillin in oil is sufficient to cure $9^{8}$ per cent of patients with gonorrhea.

For pneumococcic lobar pneumonia, it has been shown that 100,000 units given three times a day or 200,000 or 300,000 units given twice a day is sufficient for curing 95 per cent of patients.

One of the reasons that there are such wide variations in the time-dose schedules is that in most infections more 


\section{PENICILLIN}

penicillin is given than is necessary to obtain excellent results.

In summing up the question of dosage, then, it can be said that the decision concerning the total daily dose of penicillin and the time-interval between injections will depend upon the type and location of the infection, the selection of the dosage form (i.e., oral, aqueous solution, penicillin in oil and wax, or procaine penicillin in oil), and most important of all the response of the patient to treatment.

We know that penicillin has been beneficial in many infections when it is given by constant intravenous or intramuscular injection or when it is injected every two, three, or four hours. We know further that penicillin in oil and wax has been effective when given once daily. Moreover, when penicillin is given by mouth every two or three hours in an amount three to five times that which is given parenterally, it is effective. Recently it has been shown that patients with lobar pneumonia may recover on either 200,000 or 300,000 units in aqueous solution given twice daily or following 100,000 units every eight hours. These observations certainly suggest that it is unnecessary to have penicillin present in the tissues constantly in order to obtain favorable results.

The final decision concerning dosage must rest with the physician who is observing the response of the $\mathrm{pa}^{-}$ tient. The trend of treatment has been to increase the amount of penicillin that is given by individual injection and to lengthen the time-interval between injections. 


\section{PENICILLIN}

REACTIONS TO PENICILLIN

One of the extraordinary features about penicillin is that it is a nontoxic drug. Reactions due to the action of penicillin upon tissues are exceedingly rare. When excessive amounts of penicillin are injected into the subarachnoid space, convulsions are likely to occur. With the use of therapeutic doses, i.e., less than 50,000 units per injection, convulsions are very rare indeed; in our own experience we have never seen such a reaction.

The common forms of reaction are due to hypersensitivity to the penicillin itself. Following intramuscular injection, the types of reaction that are observed in 1.5 to 5 per cent of patients consist of fever, skin eruptions, edema of the skin and subcutaneous tissues, arthralgias. These reactions, which resemble serum sickness in clinical features, may last from one to three weeks. They cause extreme discomfort from itching and burning of the skin, and sometimes from pains in the joints. In general, it is desirable to discontinue the penicillin and to treat the disorders with benadryl or pyribenzamine, small doses of epinephrine if necessary, and the local application of lotions for the relief of itching.

Sensitization may also follow the local application of ointments, either ophthalmic ointments or ointments for dermatoses. This type of sensitization is more frequent than that following the parenteral use of penicillin.

Contact dermatitis occurs in nurses and physicians who handle or prepare penicillin solutions. It is desirable, therefore, for all persons who frequently handle penicillin to wear rubber gloves while preparing solutions and to 


\section{PENICILLIN}

wash all penicillin from the gloves before removing them.

Sensitization may also follow the use of aerosol solutions or the use of troches for local infections of the mouth. Penicillin has caused sensitization after its use in tooth paste.

Once a patient has become sensitized, he will react to a second injection of penicillin for a long period of time, i.e., a year or longer. It is well, therefore, to proceed with great care if it becomes necessary to use penicillin a second time. It has been possible to build up a tolerance to penicillin once a patient has become sensitized by giving small doses such as 1000 units at intervals of a day or more. On the whole, however, one must proceed cautiously.

Sensitization following the injection of penicillin in oil and wax has been reported somewhat more often than for aqueous penicillin, so that this must be taken into account when the preparation is used. In general, it has never occurred in more than 5 or 7 per cent of the cases.

\section{BACTERIAL RESISTANCE}

It is now well established that prolonged and repeated exposure of various bacteria to penicillin in vitro will select certain organisms that are increasingly resistant to its action. Some strains of staphylococci are highly resistant to penicillin before they are ever exposed to it. Other resistant strains emerge during treatment of patients. It is a curious fact that resistant strains of gonococci, pneumococci, and group A hemolytic streptococci have not been encountered in human infections. There have been some strains of nonhemolytic streptococci that 


\section{PENICILIIN}

are naturally resistant to penicillin or become more resistant following treatment. In general, however, penicillin failures have not been due to resistant organisms. The widespread use of penicillin has not led to the production of a large number of penicillin-resistant organisms. The risk of producing such strains seems to be minimal.

SOME RESULTS OF PENICILLIN

We can now turn our attention to some of the results that have emerged from the use of penicillin in medicine and surgery.

Meningitis. Sulfadiazine continues to be the drug of choice for the treatment of meningococcic meningitis. Penicillin should be used in these cases only after sulfadiazine has failed to bring the disease under control within forty-eight hours. When penicillin is used, both the intramuscular and the intrathecal route should be employed.

In the treatment of pneumococcic, hemolytic streptococcic, and staphylococcic meningitis, penicillin and sulfadiazine should both be used. Sulfadiazine by mouth and penicillin intramuscularly and intrathecally should be given to all patients with these forms of meningitis.

There is some difference of opinion concerning the advisability of giving penicillin intrathecally for patients with any form of meningitis. In the first place, it is known that very little penicillin diffuses into the cerebral spinal fluid even when meningitis is present and when large amounts are given parenterally. It is also recognized that a certain number of patients with bacterial meningitis recover when penicillin is given only parenterally. 


\section{PENICILLIN}

In our own experience, however, and in the experience reported to the Committee on Chemotherapy during the study program, the recovery rate was higher in those patients who received penicillin intramuscularly and intrathecally. Moreover, it has been shown that better results are obtained from both penicillin and sulfadiazine than when either one is given alone.

Lung Abscess and Bronchiectasis. In acute lung abscess, due to organisms that are susceptible to penicillin (staphylococcus, hemolytic streptococcus, spirochetal infection), the results of penicillin treatment have been excellent. Early treatment and postural drainage are important. When the abscess is due to Klebsiella pneumoniae, streptomycin is the drug of choice; and when the organisms are mixed, then both penicillin and streptomycin should be used together.

Bronchiectasis and Chronic Bronchitis. The results of penicillin treatment in bronchiectasis have been palliative and not curative. Aerosol inhalations in amounts of 150,000 to 500,000 to $1,000,000$ units daily have been adequate for the control of a number of the acute exacerbations of infection. The sputum decreases in amount and the cough in frequency. One feature that is likely to be striking is the disappearance of penicillin-sensitive organisms and the predominance of gram-negative bacilli of the coli-aerogenes group. In some instances, it is well to use streptomycin as well as penicillin in the aerosol solutions in an attempt to eliminate gram-negative as well as gram-positive bacteria from sputum cultures.

Crystalline penicillin dissolved in physiological saline would appear to be the preparation of choice. 


\section{PENICILLIN}

Pulmonary Infections. Pneumonia due to the pneumococcic hemolytic streptococcus or staphylococcus all respond to penicillin in a striking manner. Since pneumonia due to the pneumococcus is the commonest bacterial pneumonia in medical practice, one may well consider its management. First of all, the fatality rate in pneumococcic pneumonia following penicillin is between 3 and 5 per cent. Most of the deaths have occurred in patients who are treated late in the course of their disease, i.e., after the third or fourth day and in patients over 60 years of age with complicating diseases. The pneumococcus is very sensitive to the action of penicillin; therefore penicillin in aqueous solution in 100,000 units every eight hours, or 200,000 or 300,000 units in aqueous solution every twelve hours, is usually adequate for optimum results. Patients also respond well to 300,000 units of penicillin in oil and wax or 300,000 units procaine penicillin in oil. Successful results have also been obtained through the use of penicillin by mouth, with an initial dose of 200,000 units followed by 100,000 units every two hours.

Pneumonia caused by the hemolytic streptococcus and staphylococcus is not common, but penicillin has proved to be highly effective in treatment. Both infections are likely to lead to abscess of the lung, so that prompt treatment is necessary. Pneumonia due to the staphylococcus is more difficult to treat than streptococcus pneumonia because the organisms are more resistant; however, 200,000 or 300,000 units of penicillin daily is usually adequate. In our own experience in the 


\section{PENICILLIN}

past seven years, staphylococcic pneumonia is seen most often as a complication or secondary infection in patients with epidemic influenza.

Bacterial Endocarditis. Acute bacterial endocarditis due to the pneumococcus, the staphylococcus, the hemolytic streptococcus has responded favorably in 40 to 70 per cent of cases. The recovery rate has been lowest in the pneumococcic cases and highest in the hemolytic streptococcic cases. Inasmuch as many of these cases occur as a part of a general septic state in which the endocarditis was only one feature of the illness, it is not surprising that the recovery rate varied. The minimum daily dosage in these cases should be at least 500,000 units. The doses should be divided into equal parts and given every four or six hours throughout the day.

Subacute Bacterial Endocarditis. Prior to the introduction of penicillin, subacute bacterial endocarditis was a fatal disease in at least 95 per cent of cases. A few patients recovered spontaneously, a few recovered following sulfonamide or arsenic therapy, a few recovered following the ligation of a patent ductus arteriosus when there was a superimposed infective endocarditis, but by and large most patients with this disease died within a period of six to eighteen months after the onset of the disease.

With the use of penicillin the outlook for these patients changed. Now, at least 70 per cent of patients recover and have an arrest of their disease. The largest number of patients will recover when 500,000 units a day are given for at least six to eight weeks. When less than a 
half million units are given a day, few patients recover and the relapse rate is higher. Deaths are due to the primary infection, to heart failure, to pulmonary embolism, or to all three. Many of the patients who recover remain well for one to three years or more and show no signs of a progressive disease. Patients who show signs of heart failure at the time treatment is started usually fail to recover completely, and if they recover from the signs of infection, often die within six months to a year with cardiac insufficiency.

If relapse of infection occurs, it is usually seen within two weeks or two months after treatment is discontinued.

Clostridial Infections. The various strains of clostridia are sensitive to the action of penicillin in vitro and in clinical infections. In all cases of clostridial infection, penicillin is only an adjunct to surgical treatment, since the adequate surgical removal of all necrotic and devitalized tissue is the most important therapeutic procedure in the management of these infections. Penicillin in doses of 500,000 to 1,000,000 units a day should be used early in the course of the disease, and since most infections are mixed, it is well to combine the treatment with sulfonamides.

Actinomycosis. The best results in the treatment of this infection have been with the combined use of penicillin and sulfadiazine. When it is possible to remove infected tissues, one should do so. Altemeier has had a broad experience in this field. When sinuses are superinfected with staphylococci, these organisms disappear promptly, and the sinuses may heal completely, but recurrences in such cases are not unusual. 


\section{PENICILLIN}

Anthrax. Anthrax responds well to penicillin, and this drug is the treatment of choice. For the localized form of disease 100,000 to 200,000 units daily for three to seven days are adequate. When bacteremia is present, the treatment must be more intense and must be continued for a longer period of time.

Diphtheria. Antitoxin should be used in treating all patients with diphtheria. Penicillin will frequently cause the diphtheria bacilli to disappear from the throat at a more rapid rate than when antitoxin is used alone. Our practice has been to use it in all cases, since the carrier rate is thus reduced following acute diphtheria. Treatment requires 200,000 units daily for seven to ten days. The treatment of chronic carriers is more difficult, and while organisms disappear after seven to fourteen days' treatment following 300,000 units daily, one occasionally encounters failures.

In addition to the specific diseases mentioned, penicillin has proved to be the best chemotherapeutic agent for the treatment of acute and chronic osteomyelitis, otitis media, and mastoiditis. Penicillin is the drug of choice for the treatment of all infections due to grampositive microörganisms such as the staphylococcus, pneumococcus, and hemolytic streptococcus. It is also the best agent for the treatment of syphilis and gonorrhea.

Penicillin as a Prophylactic Agent. Penicillin has been used to prevent invasive infections when the normal defense mechanism of the body ruptured, as occurs following dental extraction, surgical removal of a lobe of a 
I. PENICILIIN

lung, or operation in an infected field. Likewise, it has been employed to prevent streptococcic sore throat in rheumatic subjects.

Prophylactic penicillin has proved to be very effective in preventing infection following thoracotomy for exploratory surgical procedures or for esophagectomy, also for the prevention of empyema following lobectomy or pneumonectomy; although in the case of lobectomy the incidence of infection was moderately high when bronchopleural fistulae developed. As a prophylactic measure in preventing infection after operations on bones and joints, penicillin has produced highly favorable results.

Infection has been prevented in 80 per cent of compound fractures, and when infection has recurred, the organisms present have been gram-negative bacteria or occasional cases of staphylococcus infections. All infections have remained localized, and no cases of generalized infection have been reported.

To reduce the incidence of infection in patients who require skin grafting or to facilitate successful grafting in the presence of infection or contamination, penicillin has been found useful.

In an attempt to reduce the number of cases of bacteremia following tooth extraction in patients with rheumatic heart disease or previous attacks of subacute bacterial endocarditis, penicillin has been used with success. Various dosage schedules have been employed, including 50,000 units twenty minutes prior to tooth extraction as a single injection or 50,000 units intramuscularly every two hours for twelve doses prior to extraction. 
I. PENICILLIN

In summary, then, one may say that within a few years penicillin has made an extraordinary change in the outlook and prognosis of many infections. No other nontoxic agent has done so much for so many infectious diseases. It is a truly remarkable agent. 


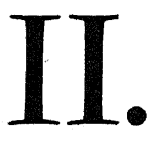




\section{II.}

\section{Streptomycin in the Treatment of Infections}

$S_{\text {treptomycin was described in }}$ 1944 by Schatz, Bugie, and Waksman. The active substances are the product of the growth of Streptomyces griseus, one of the higher bacteria found in heavily manured soil, although the original strain was isolated from the throat of a chicken. Streptomycin is active against both gram-positive and gram-negative organisms as well as the tubercle bacillus. The toxicity of streptomycin for man and animals is low, and this antibiotic is active against a number of infections in man.

Recent studies have demonstrated the fact that streptomycin as it was originally defined is not a single chemical entity but a mixture of at least two chemically related substances. The major constituent, sometimes known as Streptomycin A, is now known to be an o-glycoside of the disaccharide streptobiosamine with streptidine. The second constituent, sometimes known as Streptomycin B, is o-mannosido-N-methyl-L-glucosaminido-streptosido-streptidine.

In addition to these two substances the organism produces at least two and possibly three or more antibiotics. One is produced by the mycelium and has re- 


\section{STREPTOMYCIN}

mained unnamed. Another, designated as "actidione," is found in the culture filtrate and is active only against fungi.

Waksman has recently suggested the following nomenclature, which may be adopted:

Streptomycin complex-a term applied to all crude or partially purified preparations containing various forms of streptomycin and inactive impurities in unknown proportions.

Streptomycin-the compound formerly known as Streptomycin A, or N-methyl-L-glucosaminido-streptosido-streptidine.

Mannosidostreptomycin-the compound known as Streptomycin B.

Streptomycin residue-substances which remain after the removal of purified streptomycin from impure streptomycin, and which may have antibiotic properties or act as enhancement factors.

Streptomycin-like substances-any preparations, produced by the organism, which show an antibiotic spectrum and other biological and chemical properties similar to those of streptomycin. One such substance has been designated Streptomycin II by Johnstone and Waksman.

Streptomycin complex is an organic base which readily combines with acid radicles such as the hydrochloride and the sulfate or with calcium chloride to form the double salt calcium chloride streptomycin complex. All of these salts are available, and while the complex is a mixture of streptomycin and mannosido-streptomycin, 
both substances have an antibiotic spectrum. The latter differs quantitatively from the former. Only time and experiment will determine whether pure compounds are capable of producing more favorable chemical results than the complex and also whether one product is more toxic than the other.

What I shall say here applies to the use of streptomycin complex in the treatment of infections in man.

The streptomycin salts are readily soluble in water or glucose solution, so that one gram can be dissolved readily in one or two milliliters of fluid. Absorption from the muscles occurs promptly following injection, but practically none is absorbed from the gastrointestinal tract.

Most of the streptomycin is excreted by the kidney into the urine and some is excreted in the bile. Very little diffuses into the cerebrospinal fluid, but it passes into the various tissues of the body so that it can be found in the pleural, peritoneal, and ocular fluids in concentrations lower than that of the blood. It passes through the placenta and is found in the fetal circulation.

BACTERIAL RESISTANCE AND SENSITIVITY

It is now generally recognized that there is a great variation in the sensitivity of various organisms to the action of streptomycin. It is desirable to know about the sensitivity of the organism that is causing infection in order that enough streptomycin may be given for the concentration in the blood and tissues to inhibit the growth of the infecting organism. Table 1, taken from a paper by Murray, Paine, and Finland, lists the reported 


\section{STREPTOMYCIN}

range and the sensitivity most frequently encountered in a wide variety of microörganisms. This table clearly indicates that there is a wide variation in the sensitivity of different organisms to streptomycin. It is striking that there is also considerable variation from one strain to another within the same species.

Inasmuch as it has been demonstrated that in the presence of blood or serum the tolerance of microörganisms to streptomycin may be increased four to eight times, it is desirable to maintain a concentration in the blood four to eight times that necessary to inhibit completely the growth of organisms in vitro.

A notable feature of the use of streptomycin in the treatment of infections is the rapidity with which many bacteria acquire resistance to it. That is to say, after treatment with the drug, organisms appear in local foci of infection that cannot be killed by concentrations obtainable by the clinical use of the drug. The rapid development of resistance should encourage one to adopt the maximum dosage that is indicated in the very beginning of treatment. While it has not been demonstrated that all resistant bacteria are virulent and cause continuing infection, the appearance of resistant organisms may account for a number of streptomycin failures.

SIDE REACTIONS

There are two important side reactions to streptomycin: neurologic disturbances, characterized by tinnitus, vertigo, or deafness; and hypersensitive reactions, characterized by fever, skin eruptions, and eosinophilia. Pain in the muscles at the site of local injection is com- 
II. STREPTOMYCIN

TABLE 1

SENSITIVITY OF VARIOUS ORGANISMS TO STREPTOMYCIN

Organism

Reported Sensitivity ${ }^{1}$

Range Frequent

Actinomyces bovis

Aerobacter aerogenes

Bacillus anthracis

4

Bacillus cereus

$0.5-128$

$6-25$

0.5

Bacillus megatherium

$0.8-2$

Bacillus subtilis

$0.25-8$

Brucella abortus

$0.1-128$

1-8

Brucella melitensis

$0.5-4$

Brucella suis

$0.5-2$

Clostridium perfringens (Welch bacillus)

$0.5-3$

Clostridium septicum (Vibrion septique)

$>104$

Clostridium sordellii

$>105$

Clostridium tetani

$>105$

$>104$

Coccidioides immitis

$>300$

Corynebacterium diphtheriae

Diplococcus pneumoniae (pneumococcus)

$0.4-4$

4-50

Diphtheroids

Eberthella typhosa

$1->128$

$1-120$

$1-16$

Erysipelothrix muriseptica

Escherichia coli (various strains)

Haemophilus ducreyi (chancroid)

2.5

$0.3-128$

$1-5$

Haemophilus hemolyticus

Haemophilus influenzae (Pfeiffer's bacillus)

$0.8-3$

Haemophilus parainfluenzae

$1-50$

2.5

Haemophilus pertussis

1-15

$>2500$

Klebsiella ozaenae

$0.2-1.5$

Klebsiella pneumoniae

(Friedländer's bacillus)

Listerella monocytogenes

$0.2-128 \quad 0.6-8$

2.5 
TAble 1 (cont.)

\begin{tabular}{|c|c|c|}
\hline \multirow[t]{2}{*}{ Organism } & \multicolumn{2}{|c|}{$\begin{array}{r}\text { Reported Sensitivity }{ }^{1} \\
\text { Most }\end{array}$} \\
\hline & Range & \\
\hline Malleomyces mallei (glanders) & $10->10$ & \\
\hline Mycobacterium tuberculosis (avian) & $10-50$ & \\
\hline Mycobacterium tuberculosis & & \\
\hline (human and bovine) & $0.1-1$ & \\
\hline Neisseria catarrhalis & $1-4$ & \\
\hline Neisseria gonorrhoeae (gonococcus) & $5-40$ & $10-15$ \\
\hline Neisseria intracellularis (meningococcus) & $1-40$ & \\
\hline Nocardia & $4-12.5$ & \\
\hline Pasteurella pestis (plague) & $0.5-1.5$ & \\
\hline Pasteurella tularensis & $0.1-0.3$ & \\
\hline Paracolon bacillus & $2-128$ & $2-16$ \\
\hline Proteus morgani & $1-128$ & $8-50$ \\
\hline Proteus vulgaris & $0.4-128$ & $4-25$ \\
\hline $\begin{array}{l}\text { Pseudomonas aeruginosa } \\
\text { (Bacillus pyocyaneus) }\end{array}$ & $2-200$ & $8-50$ \\
\hline Salmonella (various species) & $4^{-120}$ & $4-32$ \\
\hline Sarcina lutea & 0.25 & \\
\hline Serratia marcescens (Bacillus prodigiosus) & $1-64$ & \\
\hline Shigella (various species) & $0.2-8$ & $3-7$ \\
\hline Staphylococcus albus & $1-256$ & $1-4$ \\
\hline Staphylococcus aureus & $0.5->128$ & $1-8$ \\
\hline Streptococcus faecalis & $12.5-60$ & \\
\hline Streptococcus hemolyticus & $1->128$ & $2-32$ \\
\hline Streptococcus, nonhemolytic & $1->128$ & $1-32$ \\
\hline Streptococcus viridans & $0.1->128$ & $1-32$ \\
\hline Streptomyces (various species) & $0.4^{-12.5}$ & \\
\hline Veillonella gazogenes & 10 & \\
\hline Vibrio comma (cholera) & $5->500$ & \\
\hline
\end{tabular}

${ }^{i}$ Minimum inhibiting concentration of streptomycin in micrograms per cubic centimeter of culture. 
plained of by a number of patients regardless of the preparation used. It is more frequent when large amounts0.5 to $1 \mathrm{gm}$.- -are given at a single injection in relatively large volumes of fluid; that is, more than 2 cubic centimeters. It is desirable to change the site of injection frequently and to use as small a volume of streptomycin as possible. One cubic centimeter of 1 per cent solution of procaine hydrochloride may be given with each injection to minimize pain.

Histamine-like reactions were described when streptomycin was first introduced. These are no longer encountered because the method of preparation has eliminated histamine from the product.

Sensitization reactions are characterized by fever and skin eruptions in about 5 per cent of patients. The eruptions may be erythematous, urticarial, maculopapular, or even hemorrhagic. The rashes appear most often between the third and tenth day of treatment, but they may be observed as early as the second day. Sometimes they do not occur until after treatment has been stopped. Their duration is extremely variable. They may be transitory and disappear within one to three days in spite of continuation of treatment, whereas in other cases they may last for seven to nine days after treatment is discontinued. Skin eruptions may or may not be accompanied by fever. When fever is present it usually persists for one to five days. Rarely fever occurs without skin eruption.

When patients have developed a skin eruption following streptomycin, they frequently react to a single injection at a later date, with the reappearance of a rash or 


\section{STREPTOMYCIN}

fever. One should, therefore, ask every patient who is about to receive streptomycin whether or not he has received it previously. The longer the interval of time between the initial hypersensitive reaction and the reinjection, the less likely one is to observe the recurrence of fever and a skin rash following a reinjection.

In general it is advisable to stop streptomycin if the skin eruption appears. Certainly the dosage should be reduced, and if treatment is continued it should be carried forward with considerable caution. Relief from the burning and itching that may be associated with the skin eruption may be obtained by the use of benadryl in 50to 100-mg. doses three or four times a day.

Eosinophilia. Eosinophilia as a sign of hypersensitivity to streptomycin was first reported by $\mathrm{McDermott}$. The eosinophiles may be 5 per cent or higher, and the eosinophilia may continue throughout treatment. It may be an accompanying feature of the skin eruption, but it may also appear without any eruption whatsoever. So far there has been no correlation between the eosinophilia and the onset of neurologic symptoms, although the two are occasionally present in the same patient.

Neurologic Disturbances. The three neurologic abnormalities that have been described are disturbances in equilibrium (vertigo without the rotary component), deafness, and tinnitus. Occasionally patients have complained of paresthesias in the region of the second and third branch of the fifth cranial nerve. Also, there has occasionally been some transitory blurring of vision in patients. These complaints are usually temporary and 
II. STREPTOMYCIN

disappear within several days after the drug has been discontinued.

Vertigo. In virtually all patients receiving as much as 3 gm. of streptomycin a day, vertigo has been observed between the seventeenth and twenty-fifth days. It is much less frequent when smaller doses are used; that is, 0.5 to $1 \mathrm{gr}$. a day for five to fourteen days. When the disturbance in equilibrium occurs early, it is most often complained of during the first five days. It may be severe or mild, and it may last from one day in the very mild cases to thirty or sixty days in the severe ones; in some cases it has persisted for as long as six to nine months. In the patients described by McDermott, all were completely free of symptoms at the end of four months. In one out of ten patients with disturbances of equilibrium, the symptom is severe. It may be associated with nausea and vomiting. In half the patients it is moderately severe, and in about a third it is negligible. Disturbance in equilibrium is most noticeable after sudden movement such as turning over or sitting up in bed, but at the height of the reaction patients are uncomfortable even when lying flat. The acute symptoms persist for seven to ten days and then gradually subside to such a degree that only an unusual stimulus like sudden shaking of the head produces transitory symptoms. Rarely, patients continue to feel unsteady at the beginning of walking or after rising from a chair, and this condition may persist for a number of months.

Deafness. This reaction has been reported under several different circumstances: first, when very large daily 


\section{STREPTOMYCIN}

doses of streptomycin-6 to 9 gm.-are used; secondly, in patients with marked renal insufficiency; and thirdly, in patients who have meningitis and receive the drug intrathecally. The deafness varies tremendously, both in degree and in duration. In some cases it is transitory and is often associated with tinnitus. This is particularly true of patients who have become deaf after receiving relatively small amounts of streptomycin within the first week of treatment. In others the deafness is permanent, and it may be complete or the hearing may be reduced by approximately 50 per cent.

Tinnitus. This is a frequent complaint and may be associated either with deafness or with disturbances in equilibrium. It has occurred in approximately 5 per cent of the cases reported to the Committee on Chemotherapy. It usually disappears following the discontinuance of streptomycin.

\section{ROUTES OF ADMINISTRATION}

There are three common routes of administration of streptomycin: intramuscular, subcutaneous, and topical, including intrathecal, intraperitoneal, and intrapleural. Solutions may be dropped into the conjunctival sacs, into the nasal passages, or into the external auditory canal. The drug has been given by means of gauze soaks on cutaneous areas and by inhalation, and it has also been introduced into the urinary bladder and kidney pelves.

The oral route is employed when a local effect in the intestinal tract is desired, but this route is of no value in the treatment of systematic infections, for the reason that so little streptomycin is absorbed from the gastrointestinal tract. 
II. STREPTOMYCIN

For all systemic infections, the intramuscular route is the one of choice. Streptomycin may be given subcutaneously, but it is more likely to cause pain and local irritation by this route than by the intramuscular one. In the treatment of meningitis, both intramuscular and intrathecal injections are necessary for optimum results. In empyema, intrapleural injections are desirable; in peritonitis, intramuscular and in some cases intraperitoneal injections are required. There is no advantage in giving streptomycin intravenously, since it is readily absorbed from the muscles:

Intramuscular Injections. When the intramuscular method is used, the maximum serum or plasma concentrations of streptomycin are obtained within one to three hours after single injections, and there is a gradual decrease in the concentration over a period of ten to twelve hours. There is a correlation between the plasma concentration and the amount of streptomycin administered. Additive effects are obtained by repeating the injections at four-hour intervals.

In general, it can be said that the total daily dose may be divided into two or four equal amounts and given every six to twelve hours throughout the day.

Following intramuscular injection, streptomycin enters the blood and passes freely into the pleural fluid, the peritoneum, the ocular fluid, and the bile. It diffuses across the placenta into the fetal circulation and amniotic fluid, and it has been found in the umbilical cord blood and amniotic fluid within ten minutes after intravenous injection into the maternal circulation. Very little strep- 


\section{STREPTOMYCIN}

tomycin diffuses into the cerebrospinal fluid. There is also evidence that it diffuses into the pus of soft-tissue abscesses, and it can be found in the kidney and other tissues of the body in varying concentration following intramuscular injection. While the drug diffuses into the pleural and peritoneal fluid, the concentration is usually lower than that of the blood. The same is true for bile, ocular fluid, and the fetal blood and amniotic fluid.

In brief, then, streptomycin diffuses from the blood into the body fluids and tissues, but the concentration in the various tissues is usually much lower than that in the circulating blood.

There is no good evidence that streptomycin is destroyed in the body. Most of it is excreted by the kidneys into the urine; small amounts are excreted into the bile and appear in the feces. At least 60 to 80 per cent of the streptomycin that is injected intramuscularly may be recovered in the urine within a 24 -hour period.

Subcutaneous Injection. It has already been stated that intermittent subcutaneous injection may be used in place of intramuscular injection. It is much more likely, however, to cause pain and local irritation, and this route has no advantage over the intramuscular one. Maximum plasma concentrations are observed within two to three hours after subcutaneous injection.

Intrathecal Injection. Following intrathecal injection streptomycin leaves the subarachnoid space slowly, so that relatively high concentrations can be detected in the cerebrospinal fluid throughout a 24 -hour period following a single injection of as little as $20 \mathrm{mg}$. The average 
II. STREPTOMYCIN

amount injected intrathecally should be 25 to $50 \mathrm{mg}$. daily; in some cases it may be necessary to use as much as $100 \mathrm{mg}$., but this amount should not be exceeded and should be used only when an unfavorable response has been obtained with smaller dosage in patients with bacterial meningitis.

Oral Administration. So little streptomycin is absorbed from the gastrointestinal tract that it should not be given by this route unless one is anxious to reduce the total number of bacteria in the stools. This method of therapy has been used as a prophylactic measure in preparing patients for surgical operations on the large bowel. It has also been employed without much success in the treatment of local and systemic infections beginning in the intestine, such as typhoid fever and Salmonella infections. Two to $3 \mathrm{gm}$. a day by mouth may be necessary to reduce the number of bacteria in the stools.

Inhalation. Streptomycin can be inhaled in aerosolized solutions for the treatment of bronchopulmonary infections due to gram-negative bacilli, or it may be combined with penicillin when a mixed infection is present. Concentrations of $50 \mathrm{mg}$. per cubic centimeter may be inhaled after the drug has been nebulized, so that a total amount of $500 \mathrm{mg}$. in a 24 -hour period is administered in this way. Only small amounts of streptomycin are absorbed from the lungs, so that very little is detected in the blood plasma and small amounts may be recovered from the urine.

RESPONSE IN VARIOUS DISEASES

Tularemia. All clinical forms of tularemia respond to streptomycin in a remarkable manner. In fact, it can be 


\section{STREPTOMYCIN}

said that streptomycin is the most important chemotherapeutic agent available today for the treatment of this disease. The results from it have been striking. This is one of the infections in which relatively small amounts of streptomycin have been used successfully. Five-tenths to $1 \mathrm{gm}$. a day in divided doses every six hours for six days is usually adequate to control either the ulceroglandular or the pneumonic form of tularemia. Intermittent intramuscular injections given over a period of six days are usually followed by a period of rapid decrease in the temperature within forty-eight to seventy-two hours and by improvement in the constitutional symptoms. There is a more gradual decrease in the size of the lymph nodes, often without suppuration, and a slow regression of the $\mathrm{X}$-ray and physical signs of pneumonitis when they are present. The clinical results of treatment have been extremely impressive in the typhoidal form of the disease, as well as in the ulceroglandular and pulmonary forms.

All patients suspected of having tularemia should be treated promptly, for the reason that the results are so striking and impressive.

Brucellosis. Experimental studies of brucellosis in guinea pigs showed quite clearly that when the infection is treated early-that is, within one week after inoculation-and when adequate amounts of streptomycin are given daily for a period of at least three weeks, the infection may be controlled and organisms eliminated from the body. Many strains of Brucella are highly susceptible to streptomycin in vitro. The results of the treatment of human infections, however, have on the whole been very 
disappointing, for the reason that these organisms seem to be extremely resistant in the body. It is generally agreed by those who have studied cases of acute brucellosis that no dramatic effects are observed in any case with the treatment schedules that have been employed.

During treatment with streptomycin the blood is often cleared of organisms if there is a bacteremia, and the temperature has returned to normal in one-third of the cases. There is very little evidence that the febrile phase of the disease has been shortened, except in those cases in which the disease has been treated within the first two or three weeks after the onset of symptoms.

The fatality rate has not been decreased so far, although the total number of cases reported is small. The febrile relapse rate is approximately 9 to 10 per cent in patients who have been treated. The blood has been cleared of organisms in 80 per cent during treatment, although in 10 per cent of patients there has been a relapse of the bacteremia as soon as treatment has been stopped, and in approximately another 10 per cent the organisms are never cleared from the blood by ten days to two weeks of treatment. A dosage of $2 \mathrm{gm}$. a day for periods of two weeks is suggested during the acute febrile phase of this disease when symptoms have been present for less than four weeks. There is no evidence that streptomycin has had any effect on the chronic cases of brucellosis, although during an acute exacerbation with bacteremia one may be able to clear the blood and to bring about a decrease in the temperature. Recent studies have shown that when sulfadiazine is combined with strepto- 


\section{STREPTOMYCIN}

mycin and continued for four weeks, excellent results have been obtained in the acute cases.

Typhoid fever. Streptomycin has produced no dramatic effects in typhoid fever. It has not decreased the fatality rate nor the relapse rate. There is some suggestive evidence that in patients treated during the first ten to fourteen days of their illness the febrile period of the disease is shortened. There is no evidence that treating patients after the fourteenth day of illness influences the disease in any way.

Salmonella Infections. The results in the treatment of Salmonella infections, both those that produce acute gastroenteritis and those that cause enteric fever, have been disappointing. Occasionally one sees a temporary disappearance of organisms from the stools following the oral and systemic administration of streptomycin, but the total duration of the disease does not seem to be shortened. It is not clear why the results have been so unsatisfactory in patients who have an infection due to organisms that are susceptible to streptomycin in vitro.

Endocarditis. Most cases of bacterial endocarditis are due to gram-positive microörganisms that are sensitive to the action of penicillin. A few cases are due to gram-negative bacilli or to organisms that are penicillinresistant and streptomycin-sensitive. Such cases have been studied especially by Hunter at the Presbyterian Hospital in New York City. On the basis of the experience reported by him, streptomycin should be given a trial in all infections due to gram-negative bacilli or to penicillin-resistant gram-positive cocci, and in infections that have failed to respond to penicillin therapy. 
The dosage recommended by Hunter is 2 to $6 \mathrm{gm}$. a day for a period of two to four weeks, depending on the sensitivity of the organism and the clinical response. In some cases of endocarditis caused by microörganisms that show in vitro sensitivity to both penicillin and streptomycin, a course of therapy with both drugs together has been used with success. It should be emphasized that when large doses of streptomycin are given, such as 4 to $6 \mathrm{gm}$. a day for two to four weeks, neurologic symptoms are likely to occur. Some patients may even develop deafness, and for this reason audiometer and vestibular function tests should be made at regular intervals during treatment.

Peritonitis. Experimentally streptomycin reduces the fatality rate in animals with peritonitis, and it has been recommended along with penicillin and the sulfonamides in the treatment of all cases of established peritonitis in man. There now exists suggestive evidence that streptomycin has had a beneficial effect in a number of cases of peritonitis due to gram-negative bacilli. In some instances the organisms are mixed, and in others single strains are responsible for the peritonitis. It is recommended, therefore, that streptomycin be used along with other chemotherapeutic agents, and other established forms of treatment, in all cases of peritonitis.

Wound Infections. The treatment of established infections of wounds is a complicated procedure. The use of penicillin and the sulfonamides will prevent invasive infections due to susceptible organisms in wounds. These drugs aid in the sterilization of local foci of infection. 


\section{STREPTOMYCIN}

Sooner or later gram-negative bacilli appear in all chronicinfected wounds, and they may dominate the bacteriologic flora. There are those who hold that gram-negative bacilli do not interfere with the healing of wounds, but the studies of Howes stress the fact that they definitely do so. Howes has also presented good experimental evidence that streptomycin can be given topically to rid wounds of persistent gram-negative bacilli when no slough is present.

On the basis of these observations it can be said that a solution of streptomycin in a concentration of $200 \mathrm{mg}$. per cubic centimeter can be used in freshly wounded tissues without further damage, and that wounds so treated heal without delay. Furthermore, it has been shown that granulations are not damaged by a thousand units of streptomycin per cubic centimeter. Streptomycin, then, can be said to be the best nontoxic antibiotic that has been discovered so far for destroying gram-negative bacilli.

It has been recommended that penicillin in concentrations of a thousand units per cubic centimeter or 5 per cent sulfamylon should be combined with streptomycin when it is used topically. The purpose of this combined chemotherapy is to assist in the killing of susceptible bacteria of both the gram-positive and gram-negative groups. As adjuvants to therapy, when slough is present, Howes has demonstrated that resolution of the established localized infection can be hastened by the use of chemicals that will liquefy slough and permit antibacterial substances to penetrate and kill the bacteria that remain. 


\section{STREPTOMYCIN}

Shigella Infections. A few patients with sulfonamideresistant bacillary dysentery have been treated with streptomycin given by mouth in doses of $5 \mathrm{gm}$. a day for four days. Diarrhea and fever subsided in twelve hours and the causative organisms disappeared from the stools. There is suggestive evidence, therefore, that certain cases of bacillary dysentery that are resistant to the sulfonamides may respond in a striking manner to streptomycin by mouth.

Cholera. Streptomycin has been used in the treatment of a few patients with cholera. It was given by mouth in doses of $4 \mathrm{gm}$. a day, with an occasional intravenous injection. There is no clear indication that it had any advantage over large amounts of fluid and the sulfonamides. It is true, however, that the number of cholera Vibrio diminished in the stools following treatment, although some were still present there and had increased in resistance.

Infections of the Eye. Corneal ulcers due to Pseudomonas aeruginosa and Escherichia coli have been treated successfully by a streptomycin solution instilled into the conjunctival sac. Ps. aeruginosa ulcers of the cornea are always serious and difficult to cope with, so that streptomycin should be used in all such cases.

Infections of the Ear. Infections of the middle ear due to gram-negative bacilli have responded with great irregularity to streptomycin. Usually surgical treatment is needed along with chemotherapy if satisfactory results are to be obtained.

Urinary-tract Infections. Acute and chronic urinarytract infections due to susceptible microörganisms, usu- 


\section{STREPTOMYCIN}

ally of the gram-negative group, have responded in a remarkable way in at least 40 to 60 per cent of the cases following the use of streptomycin. Following parenteral injection 60 to 80 per cent of the amount injected is recovered in the urine within twenty-four to forty-eight hours. Streptomycin usually appears in high concentration, depending on the renal function, the volume of the urine, and the dose administered. It is much more active when the urine is alkaline, so that it is desirable to use alkalis along with streptomycin to render the urine alkaline if it is not already so. In susceptible cases the urine is usually sterilized within a period of seventy-two hours. Failure to sterilize the urine within this period of time is generally due to resistance of the infecting organism, the presence of an obstruction in the urinary tract, an undiscovered abscess, or a foreign body. It is practically impossible to sterilize the urine when there is an inlying catheter or when stones are present.

The commonest microörganism causing urinary-tract infections are Escherichia coli, Aerobacter aerogenes, Proteus vulgaris, Pseudomonas aeruginosa, and Streptococcus faecalis. At least 75 per cent of the strains of Esch. coli, $\mathrm{P}^{-}$vulgaris, and A. aerogenes are sensitive to a concentration of $20 \mathrm{mg}$. per cubic centimeter of streptomycin. Strains of Strept. faecalis and Ps. aeruginosa are often extremely resistant in the very beginning and require concentrations of at least $100 \mathrm{mg}$. or more to inhibit their growth. When streptomycin is given to patients with acute or chronic pyelonephritis, constitutional symptoms and signs of infection frequently disappear promptly. 
Clinical improvement occurs in 50 to 60 per cent of the patients within a 72 -hour period. Symptoms referable to the urinary tract respond more irregularly.

It has been our experience that when the urinary output is restricted to 2000 cubic centimeters a day and the daily dose of streptomycin is $1 \mathrm{gm}$., the concentration of streptomycin in the urine averages about $100 \mathrm{mg}$. per cubic centimeter. This is usually adequate for the treatment of most urinary-tract infections, provided other factors are favorable for sterilizing the urine. When resistant organisms such as Ps. aeruginosa and Strept. faecalis are present, a higher urinary concentration of streptomycin is desirable, and a daily dose of $2 \mathrm{gm}$. should be given. When single organisms are present, sterilization of the urine occurs in about 40 per cent of the cases. Bacteriuria is diminished, at least temporarily, in practically all patients. Infections due to a single organism generally respond much more favorably than those in which a mixed bacterial flow is present. Any patient who fails to respond within twenty-four to seventy-two hours should be suspected of having a resistant organism or some underlying anatomical lesion interfering with the free flow of urine, a foreign body, or an undrained abscess. It should be remembered that bacteria exposed to streptomycin may, if the strains have become resistant to it, often respond to other chemotherapeutic agents.

In summary, then, in the treatment of urinary-tract infections it is desirable to study the organisms that are causing infection in order to determine their resistance, and also to examine the patient for an explanation of the 


\section{STREPTOMYCIN}

underlying cause of infection. When obstructions are present, plans should be made to establish a free flow of urine or for the removal of stones. The urinary output should not exceed 2000 cubic centimeters a day. Streptomycin should be given intramuscularly in 1 -gm. doses for a period of five to seven days, and the urine should be kept alkaline during this time. It is usually unnecessary to continue treatment longer than seven to ten days unless bacteremia and an invasive infection are present. Under these circumstances it may be necessary to continue treatment for as long as two to three weeks before the infection is under complete control.

Hemophilus Influenzae Meningitis. There is now a considerable body of evidence indicating that when streptomycin is used alone for the treatment of Hemophilus influenzae meningitis, and is given both intramuscularly and intrathecally, the recovery rate is high. When the treatment is started late in the course of the disease, the results may be irregular. Streptomycin, then, should be given in all cases of $\mathrm{H}$. influenzae meningitis. It may be used alone when the disease is treated early, but if treatment is not started until late in the course of the illness, sulfadiazine and antiserum should perhaps be added.

The intramuscular dosage usually employed is $25 \mathrm{mg}$. per pound of body weight daily and 20 to $50 \mathrm{mg}$. per day intrathecally. On this regimen the organisms generally disappear from the blood and cerebrospinal fluid within forty-eight to seventy-two hours and the constitutional symptoms decrease. Treatment should be continued for 
at least seven to ten days or longer, depending on the clinical and bacteriologic response.

Meningitis Due to Miscellaneous Gram-Negative Bacilli. Occasional cases of meningitis are caused by Escherichia coli, Pseudomonas aeruginosa, Klebsiella pneumoniae, Proteus vulgaris, Alcaligenes faecalis, Proteus morganii, Salmonella choleraesuis, and Aerobacter aerogenes. The fatality rate in these cases tends to be high, although the use of streptomycin both intramuscularly and intrathecally in adequate doses early in the course of the disease has been followed by favorable results. Infections of the central nervous system by these organisms respond poorly to the sulfonamides and are not helped by penicillin. When patients are treated early it is clear that streptomycin has been responsible for recoveries, and it should be given in all cases. One gram a day intramuscularly in divided doses and 25 to $50 \mathrm{mg}$. a day intrathecally, with treatment continued for six to ten days depending on the clinical response, is the regimen to be followed.

Bacteremia. Bacteremias due to a wide variety of gram-negative bacilli, with or without localizing signs of infection, can be cleared by streptomycin in many cases and the local infection responsible for the blood invasion can be controlled. Infections with bacteremia due to a variety of organisms have been treated. These include Escherichia coli, Proteus vulgaris, Pseudomonas aeruginosa, Aerobacter aerogenes, Klebsiella pneumoniae, Hemophilus influenzae, and Salmonella. In all these cases the fatality rate has been reduced, and in patients who have recovered the streptomycin was important in con- 


\section{STREPTOMYCIN}

trolling the local infection. It is generally agreed that the prognosis in such cases is determined in some measure by the nature and severity of the local lesions from which the invasion of the blood stream occurs. In some cases, also, it is known that the bacteremia is a transitory one and often follows trauma in an infected area. The age of the patient, the site and extent of the initial lesion, the species of infecting organism, the presence of complicating and debilitating diseases, and the duration of infection must be taken into account in assessing the results of treatment. All patients with bacteremia should receive 1 to $3 \mathrm{gm}$. of streptomycin daily for a period of seven to ten days.

Pulmonary Infections. The two commonest organisms causing acute infection of the lungs that are susceptible to streptomycin are Hemophilus influenzae and Klebsiella pneumoniae. These infections may be either acute or chronic and either primary or secondary. In the chronic infections there is always some underlying anatomical lesion, such as bronchiectasis, that contributes to the infection. In the acute infections with pneumonitis due to Kleb. pneumoniae and $\mathrm{H}$. influenzae, the results of streptomycin treatment have been impressive. In the chronic infections, on the other hand, they have been transitory. $H$. influenzae infection of the lungs is seen most often in infants and young children. Here a diffuse capillary bronchitis or bronchopneumonia is frequent, and in about half the patients it is accompanied by bacteremia. Streptomycin has been highly successful in the treatment of these acute infections in infancy and child- 
II. STREPTOMYCIN

hood. In Kleb. pneumoniae infections the acute infection is often controlled so that the process does not go on to abscess formation and pulmonary fibrosis. In view of the serious character of pneumonia caused by Kleb. pneumoniae, its associated high fatality rate, and its tendency to produce multiple pulmonary cavities, prompt institution of large doses of streptomycin, preferably 1 gm. every four to six hours in adults, is indicated.

It is a common experience to observe a change in the bacteriologic flora of the sputum of patients with pulmonary infections who have been treated with antibiotic agents. Following penicillin it is not infrequent for the gram-positive organisms to disappear, or at least to become less numerous, and for gram-negative organisms to appear in large numbers. In many cases it is extremely difficult to decide what role is being played by these organisms in continuing infections. In some cases they seem to be important, for the reason that following streptomycin treatment the constitutional symptoms and signs of infection may disappear as the organisms disappear from the sputum. In some of the mixed infections it may be necessary to give both penicillin and streptomycin.

Chronic Pulmonary Infections. Chronic bronchiectasis, lung abscess, and empyema caused by gram-negative organisms may be helped by streptomycin, given either by the aerosol method or systemically. In many cases these infections are a mixed variety, so that it is necessary to use both penicillin and streptomycin. Penicillin eliminates only the penicillin-sensitive organisms, and in 


\section{STREPTOMYCIN}

some patients the infection persists owing to the presence of gram-negative bacilli which are penicillin-insensitive. In such cases the response to streptomycin has been encouraging. The number of organisms is decreased following inhalations of streptomycin and the volume of the sputum may diminish. At least $0.5 \mathrm{gm}$. of streptomycin in 20 cubic centimeters of normal physiological salt solution should be given daily. One should emphasize that streptomycin is only palliative in these cases, but it offers great relief of symptoms, and in some cases arrests the progress of the disease.

Tuberculosis. Soon after it had been demonstrated that streptomycin inhibits the growth of the tubercle bacillus in vitro, experimental studies were carried out in guinea pigs with tuberculous infection by Feldman and Hinshaw at the Mayo Clinic. They demonstrated quite conclusively that in at least 70 per cent of animals infected with tubercle bacilli streptomycin was responsible for eliminating the organisms from the body.

The most extensive studies on the effect of the drug in tuberculosis have been carried out by the Veterans Administration under the direction of Barnwell and Walker. Other important studies have been carried out by the Army and the Navy, by Hinshaw and Feldman and their associates at the Mayo Clinic, by McDermott and his associates at the New York Hospitals.

It is proper to say at once that streptomycin is the only effective chemotherapeutic agent that can be used in man for the treatment of tuberculosis. In a few cases it has been combined with promine. In some cases ex- 
II. STREPTOMYCIN

traordinary results have been observed. Let us review some of them.

Acute Miliary Tuberculosis with or without Meningitis. Patients with miliary tuberculosis without menin. gitis have recovered from their acute disseminated process in about two-thirds of the cases. These results have been obtained when patients have received $2.0 \mathrm{gm}$. of streptomycin daily for 120 days. The follow-up period has averaged four months to a year. When death occurs in this group it commonly occurs within six weeks of the initiation of treatment. In most of the fatal cases there has been no post-mortem evidence of healing of the lesion. In a few, however, evidence of healing is plain and consists of small fibrotic "hard" tubercles; many of them have lost their characteristic histologic appearance. $\mathrm{Pa}$ tients who relapse while under treatment often show an infection due to a resistant organism. In about half of the patients with miliary tuberculosis who recover from signs of disseminated lesions, meningitis appears within four weeks and four months after treatment has been started.

In patients with both miliary tuberculosis and meningitis only about 10 per cent have recovered following treatment.

In patients with meningitis without miliary tuberculosis about one-third of the patients recover from the signs of acute infection, but only about 25 per cent are relieved of all evidence of central nervous system tuberculosis. Even in these cases the protein content of the cerebrospinal fluid continues to be elevated in spite of the normal cell count. 


\section{STREPTOMYCIN}

It has been suggested by the Veterans Administration group that the dosage schedule for miliary tuberculosis should be $2.0 \mathrm{gm}$. daily in five doses and that the treatment should be continued from 90 to 180 days depending upon the response of the patient. When meningitis is present, the parenteral treatment should be combined with intrathecal injections of $0.05 \mathrm{gm}$. per day for the first week, then two or three times a week or less often as improvement takes place. In view of the favorable responses in children with miliary tuberculosis following the use of promine, it has been suggested further that 4.0 gm. a day be given intravenously for two weeks followed by a week of rest. When promine is used the blood must be watched carefully, since a hemolytic anemia may occur.

The results of treatment of these serious cases of tuberculosis may be summed up as follows:

(1) Patients with acute miliary tuberculosis recover from the signs of infection more often when there are no signs of tuberculous meningitis present at the onset of treatment.

(2) The optimum results have been obtained with $2 \mathrm{gm}$. of streptomycin intramuscularly for 120 days in divided doses five times a day.

(3) Fifty milligrams of streptomycin should be given intrathecally during the first. week, then two or three times a week as improvement occurs.

Failures are due most often to the following:

(1) The presence of meningitis. 
(2) The development of meningitis during or following the discontinuance of treatment.

(3) The development of bacterial resistance.

Progressive Pulmonary Tuberculosis. The effect of streptomycin in some patients with progressive pulmonary tuberculosis has been striking indeed. It is most impressive in the patients with acute exudative lesions and in the areas of the lung where necrosis is minimal. The optimum time-dose schedules have not been completely worked out but the immediate results as judged by X-ray examinations would appear to be similar whether 1.8 or $2.0 \mathrm{gm}$. are given daily in five divided doses for sixty or 120 days, or whether $1.0 \mathrm{gm}$. is given for sixty days, either in five divided doses or in two equal doses. Between 75 and 85 per cent of patients will show improvement on these dosage schedules. Soon after treatment is started there is often an improvement in the constitutional symptoms and signs. Fever is reduced, the appetite improves, and the patients gain weight. Within one or two months of treatment, exudates are being absorbed and there is a gradual regression of the lesions. Extensions of the lesions while patients are under treatment are infrequent unless the tubercle bacilli become resistant to streptomycin. Between 15 and 20 per cent of patients have relapses of their infections after treatment is discontinued. Only about 50 per cent of patients revert from a positive to negative sputum while under treatment, and with the continuation of treatment more than four to six weeks, the number of cases in which the tubercle bacillus 


\section{STREPTOMYCIN}

becomes resistant to increasing amounts of streptomycin increases greatly. For example, it has been shown that only about 5 per cent of strains are resistant to 10 micrograms of streptomycin per cubic centimeter after four weeks of treatment, whereas $7^{6}$ per cent of organisms are resistant after 120 days. In general, it can be said that one of the limiting factors in treating patients with tuberculosis is the development of resistant strains of tubercle bacilli. These organisms are virulent for guinea pigs. Progress of the tuberculous process has been noted in many resistant cases receiving streptomycin. In some cases, improvement was noted or continued even though resistant organisms were obtained on culture. In brief, however, streptomycin exerts little if any beneficial effect in cases with resistant organisms, and any improvement noted under these circumstances must be attributed to the natural defense mechanism of the disease.

Draining Sinuses. Patients with draining sinuses from bone or lymph node tuberculosis improve in a striking manner following streptomycin. Sixty per cent of the sinuses heal, and about 25 per cent improve. The dose of $1.0 \mathrm{gm}$. a day in two equally divided doses of $0.5 \mathrm{gm}$. each for 120 days is the advantageous dose.

Tuberculosis of the Upper and Middle Respiratory Tract. Striking results have been obtained in the treatment of tuberculosis of the upper and middle respiratory tract, including the larynx, hypopharynx, trachea, and larger bronchi. Ulcerations have healed in a remarkable manner within three to six months of treatment, and one can observe these healing lesions by direct visual examin- 
II. STREPTOMYCIN

ation. The positive effects follow both systemic and local treatment by the aerosol method. Systemic treatment appears to be the more effective of the two. The recommended dosage is 1 to $2 \mathrm{gm}$. a day intramuscularly and $0.5 \mathrm{gm}$. in divided doses by inhalation every two hours in concentrations of $50 \mathrm{mg}$. per cubic centimeter.

Tuberculosis of the Urinary Tract. Symptomatic improvement has been observed in some patients with tuberculosis of the urinary tract. The total number of tubercle bacilli decreases, and in a few cases they disappear, at least temporarily. Pyuria diminishes, and there is an increase in the capacity of the bladder and a decrease in the frequency of urination. So far, the results of treatment have not been of a permanent character, but appear to be palliative. One to $1.5 \mathrm{gm}$. a day is usually given for a period of two months or longer.

Tuberculosis of Pleura, Peritoneum, and Intestine. Too few cases have been studied to make any statements concerning the final results, but outstanding improvement has occurred in some of the cases reported after treatment for sixty to ninety days.

In summing up, then, it can be said that streptomycin has a powerful effect on the tubercle bacillus, and that this effect is reflected in the results observed in certain forms of clinical tuberculosis. This drug should be reserved for patients with a poor prognosis and for those who have an advancing lesion in spite of the usual medical treatment. It is desirable to use small doses, 1.0 to 1.5 gm. daily for the shortest possible period of time that is 


\section{STREPTOMYCIN}

consistent with maximum improvement. In this way the number of reactions are reduced and the number of strains of tubercle bacilli that become resistant is likewise reduced. Studies now in progress in various institutions in the United States should give additional information that will guide the medical profession in the future use of streptomycin.

Prophylactic Use before Operations on the Large Intestine. Zintel and his associates at the University Hospital in Philadelphia have shown that the oral administration of streptomycin reduces the total population of bacteria in the feces. They have used the drug, therefore, in doses of 1 to $2 \mathrm{gm}$. a day preoperatively, and streptomycin and penicillin postoperatively, in all patients operated on for resection of the large intestine. A greater number of such resections can be done with primary suture, and the chances of peritoneal infection are reduced, if streptomycin is employed in this way. 
III. 


\section{III.}

\section{Antibacterial Agents from Microbes}

In selecting the topic of antibacterial agents from microbes, I want to sketch for you the origin of some of our most potent anti-infectious agents thus derived. I propose introducing the subject by telling you something about the history of the discovery and the cause of anthrax. This disease is now rare but historically important. Anthrax is a disease of both animals and man. Cows, sheep, horses, mink are all affected. Man acquires infection from coming in contact with infected material, such as hides, wool, horse hair, shaving brushes. The spores have been shown to be present in the tusks of elephants and have occasionally been transmitted to man in the manufacture of the ivory tips for piano keys. It is an old disease. It has caused great economic loss throughout the ages. In our own clinic we see about two patients with anthrax every year.

I shall begin my story by telling you that in 1876 , a young practitioner of medicine in Wollstein, East Prussia, proved that the small sporulating rods found in the blood of animals dying of anthrax are the cause of the disease. He gave the name Bacillus anthracis to these microörganisms. The observation was most important, be- 


\section{ANTIBACTERIAL AGENTS}

cause it was the first time that a specific disease was shown to be due to a single and characteristic microbe. The name of the practitioner was Robert Koch, who later discovered the bacteria causing tuberculosis. Organisms had been seen in the blood of animals dying of anthrax by others before Koch, but their significance was questioned. In fact, when Koch announced his discovery there was still doubt in the minds of some of the French scientists concerning their significance, because they had been unable to find the organisms in the blood of all animals dying of anthrax. Moreover, Paul Bert, the great pupil of Claude Bernard, insisted that the disease was due to a virus, since he could expose the blood containing bacilli to high concentrations of oxygen and destroy the bacilli and still produce the disease in experimental animals.

At this stage of the controversy, Pasteur stepped in and made some experiments. He isolated the anthrax bacillus and cultured it through many generations until he felt that the organism was free of any contamination or virus. $\mathrm{He}$ then inoculated guinea pigs with the bacillus and produced anthrax. He was convinced that the organism was the cause of the disease. It remained, however, for him to explain the observations of Julliard and Leplat that not all animals dying of anthrax had this bacillus in their blood. So Pasteur took a trip to Chartres in southern France. There he found a cow dead of anthrax sixteen hours, a sheep and a horse dead of the same disease for thirty hours. The blood from the cow killed guinea pigs following injection, and anthrax bacilli were isolated 


\section{ANTIBACTERIAL AGENTS}

from the pigs. The blood from the sheep and the horse contained putrefactive organisms but no anthrax bacilli. Inoculation of animals with this blood caused death from sepsis but not from anthrax. The putrefactive organisms had killed off the anthrax bacilli. By cultural methods Pasteur succeeded in separating the aerobic anthrax bacilli from the anaerobic putrefactive organisms responsible for the deaths from sepsis. This was the first demonstration that one group of organisms could kill another. Pasteur made other observations of importance. One day while transferring anthrax bacilli from one flask to another, the media being boiled urine, the culture became contaminated with some air organisms. He set the contaminated culture aside several days and then examined it. To his surprise and consternation, he found that anthrax bacilli had disappeared. He drew the logical conclusion that the contaminating organisms were responsible for their death. He went further and showed that several different organisms were capable of killing anthrax bacilli. A few attempts were made to show the antagonistic effect of some organisms upon anthrax by injecting guinea pigs with mixed cultures. The animals did not die of anthrax. Some survived; others died of sepsis. Here, then, was further proof that the products of the growth of one bacterium killed another.

These observations created great excitement, and for some time there was considerable interest in the question of bacterial antagonism. Metchnikoff noted that the lactobacilli in the stools decreased sharply or disappeared altogether during an attack of dysentery. He reasoned 


\section{ANTIBACTERIAL AGENTS}

that one organism had killed off the other. He suggested that it might be possible to reverse the situation-that is, by increasing the numbers of lactobacilli, the pathogenic bacteria might be killed off. This idea failed to work out when it was tested experimentally.

There followed a great many observations concerning the phenomena of bacterial antagonism.

Many reports were made, and, naturally, there were attempts to apply the rapidly developing theory of bacterial antagonism to medical therapeutics. A number of bacteria were found to be antagonistic to anthrax bacillus, including B. pyocyaneus, the Friedländer's bacillus, and streptococci. Some strains of bacteria were antagonistic to the tubercle bacillus. But attempts to use pathogenic bacteria to destroy other organisms were not highly successful in the treatment of human infections.

New light was shed on this problem in 1904 when Frost found that under certain conditions, typhoid bacilli were destroyed within a few days after they were added to soil. However, under conditions that were unfavorable to the growth of soil bacteria, the typhoid bacilli could persist for months. These observations led Frost to conclude that when the soil bacteria were given the opportunity to grow and to develop by-products then they could kill the typhoid bacillus. In other words, it was the metabolic products of the bacteria that killed the organisms and not a lack of food for both organisms that caused the death of one.

The next step was an attempt to isolate from the filtrates of bacterial cultures the active antibacterial sub- 
III. ANTIBACTERIAL AGENTS

stances themselves. The first one to be isolated and used was pyocyanase, by Emmerich and Low. They found that when the filtrates of cultures of B. pyocyaneus were evaporated to one-tenth their original volume, and then tested against bacteria in vitro and in vivo, many different bacteria were killed. Here was a startling discovery, and commercial preparations began to appear on the market which for eight or nine years were used to a considerable extent in the treatment of a wide variety of infections.

Unfortunately, the results were inconsistent and irregular, so that pyocyanase was finally given up as a therapeutic agent.

It is perhaps well to pause at this point in our narrative and inquire into the causes for the irregularity in the action of pyocyanase. It has been learned that only certain strains of Ps. aeruginosa produce this substance and, moreover, it is now recognized that it must be grown on certain media in order that the active product may develop. Further, at least two substances are involved, pyocyanase and pyocyanin. Finally, it has been ascertained that these substances are toxic when given parenterally, so that they are of no use parenterally.

Following this period of excitement over the possible use of antibacterial agents derived from microbes for medical therapeutics there was a lag period in which attention was turned to other agents, such as antitoxins, bacterophage, and antiserums.

Then came the remarkable and outstanding announcement by Avery and Dubos that they had isolated an enzyme from a bacterium that was capable of destroy- 


\section{ANTIBACTERIAL AGENTS}

ing the capsular carbohydrate of the Type III pneumococcus. Once the coating of sugar had been removed from the pneumococcus and digested, the body of the pneumococcus could be devoured by the leucocytes of the body with the greatest of ease. The story of this discovery is so interesting that I want to tell you about it.

For several years, Dubos had been interested in the problems of cellulose decomposing bacteria of the soil.

Food substances of plants are derived from cellulose decomposition in soil. Microbes decompose cellulose so that food products for plants are made available. Each year a large quantity of leaves, stalks, and other cellulose material falls on every acre of forest land in the United States, and each year a large quantity of this cellulose is digested by organisms in the soil. Without the activity of these organisms, plants and trees would be deprived of food. Without the proper food, microbes will also weaken and die. It occurred to Dubos that it might be possible to find a microbe that could use the vinegar of the pneumococcus for food or at least to train an organism to digest the pneumococcus carbohydrate as a source of nourishment. Normally, organisms in soil have enough food to live in a state of symbiosis. They compete for food and living space. Since there is usually adequate space and food, organisms live alongside one another for years without lapsing into a destructive state in their struggle for survival and existence.

But Dubos asked the question, What would happen to soil microbes if they were starved or if their food supply was greatly reduced? Would they become cannibal- 
istic or would they merely die of starvation? Could organisms that were starving adapt themselves to a new and strange diet and save themselves? This question could be answered only by experiment. Therefore, he gathered samples of soil and placed them in containers carefully protected from the air. With the passage of time, as the food supply of the bacteria was used up, the organisms began to weaken. Now was the time to determine whether any of these organisms could digest the carbohydrate of the Type III pneumococcus. Many of the organisms were unable to use this sugar as a source of food, but in the containers filled with peat from a New Jersey cranberry bog were some microbes that survived. They had learned, or were at least able, to utilize the new sugar for food. After these organisms were fed a sole diet of $\mathrm{Pn}$. polysaccharide, they began to grow fat and multiply. Dubos grew them in many generations until they were accustomed to the carbohydrate diet. He then isolated from these bacteria the enzyme that was capable of digesting the carbohydrate. The substance was effective in protecting mice against infection, and it was also effective in monkeys with Type III pneumonia. It was used with some success in a few patients with Type III lobar pneumonia, but it had one very serious drawback as a therapeutic agent. It caused serious side reactions in man. In any event, it was a great fundamental discovery and stimulated a tremendous amount of investigation. Dubos went further and using somewhat the same techniques developed another substance, known as tyrothricin, an anti-infective agent, derived from an organism in 


\section{ANTIBACTERIAL AGENTS}

soil, B. brevis. This is a powerful agent that destroys both gram-positive and gram-negative bacteria. It can be used locally with success for the treatment of infections that are of a superficial nature. It cannot be used parenterally because of the fact that it is hemolytic for red blood cells and causes damage to liver and kidney cells.

While the search for antibacterial agents was going on here in the United States, other students of biology and bacteriology in England and elsewhere were busily engaged in looking for other agents.

In 1928, Dr. Alexander Fleming, now Sir Alexander Fleming, was making some observations on the degradation of staphylococci as they aged. He kept his Petri dishes on the laboratory bench. He would open them from time to time, study the morphology of the aging colonies of bacteria, and close the lid once again. One day, he noticed that a culture had became contaminated with a mold growth. He did not discard the plate as many bacteriologists might have done. He examined it carefully, and much to his surprise he discovered that in the zone around the mold the colonies of bacteria were getting smaller and in some instances had disappeared altogether. This observation excited his interest. He isolated the mold, grew it in pure culture, and showed that the filtrate from the culture media had the capacity to kill a wide variety of microörganisms in high dilution. The material was not toxic for leucocytes nor was it toxic for small animals. Since the mold was a strain of penicillium, he named the active antibacterial substance penicillin. Here, then, was a discovery that was made in the labora- 
tory by accident. But it should be remarked that one never has an accident of this sort unless he is working hard in the laboratory and that one may not appreciate the significance of any accident unless his mind is prepared to grasp its significance.

The discovery of penicillin created somewhat of a stir, which did not last very long. One of the reasons for the lack of interest in the substance was the great diffculty in producing any quantity of it for experimentation, and even then the material was extremely unstable in solution. It was about ten years after its discovery that Florey, Chain, and their associates at Oxford reopened the study of penicillin. They found that it was extremely active against bacteria and nontoxic for mice. With great effort, a sufficient amount of penicillin was produced to treat six patients successfully. The results were so promising that the scientists were stimulated to encourage its production on a sufficiently large scale to test it thoroughly. England was in the life-and-death struggle of war, so in the summer of 1941, Florey came to this country and consulted with the National Research Council and the Committee on Medical Research of the Office of Scientific Research and Development. A tremendous cooperative effort was made by the chemical and pharmaceutic industry, agencies of government, many hospitals, and universities, so that by the spring of 1942 , enough penicillin was available to treat a single patient. As production increased, more and more patients were treated, and more and more diseases were found to be brought under control by its use. In the spring of 1943, the first 


\section{ANTIBACTERIAL AGENTS}

wounded men were treated, and by D Day in 1944, there was enough penicillin available for our troops and for our allies and a moderate amount for civilians. This was a remarkable achievement in wartime, since the problems of producing penicillin were stupendous. At first, the cost was $\$ 200$ for a million units. Today the same amount costs $\$ 3.50$. This substance derived from the products of metabolism of a mold has changed completely the course of many diseases. It has saved countless lives and many, many days of illness and long suffering.

One of the most striking features of penicillin is the fact that it is effective against a group of bacteria known as gram-positive organisms, but has very little effect on gram-negative bacteria excepting the gonococcus and the meningococcus. It has no effect upon the tubercle bacillus. The search for an antibacterial agent that would control the gram-negative bacteria like the typhoid bacillus and the colon bacillus and the tubercle bacillus went on. In 1944, Dr. Selman Waksman and his two associates Drs. Bugie and Schatz announced that they had isolated a substance called streptomycin that was active against both gram-positive and gram-negative bacteria, including the tubercle bacillus. This antibiotic was derived from one of the Actinomyces that are found in heavily manured soil, but the original strain was isolated from the throat of a chicken. Scientists look in strange places for all sorts of organisms, and the throat of a chicken may be among the strangest. I may add that one of the best strains for producing penicillin was isolated from a cantaloupe in a fruit market in Peoria, Illinois. 
In any event, it was not long before streptomycin was being produced in small amounts and being tested against a wide variety of infections, including tuberculosis, tularemia, brucellosis, typhoid fever, influenza bacillus, meningitis, peritonitis, and urinary-tract infections. The results have been extremely favorable in many of these infections, and we should note that it is the only anti-infective agent derived from microbes that can be used with a positive effect in tuberculosis. While it is not a perfect agent for the treatment of tuberculosis, it is extremely effective in many cases.

There are other antibacterial agents that are being investigated, including bacitracin, derived from a strain of B. subtilus, and chloromycetin from a streptomyces. We may expect to hear about many more in the years to come.

None of these agents are in any way effective against virus infections such as influenza virus, poliomyelitis, or the virus of the common cold, and here remains a challenge to all of us. It is not too much to hope that some day agents may be found which will defeat these infections.

It is truly remarkable that the two agents most widely used, i.e., penicillin and streptomycin, are both effective against anthrax, the disease that first directed attention to the subject of bacterial antagonism. They both come from the soil.

What of the future? We have now entered one of the most stimulating periods in science, that "endless frontier." Medical science has come of age in the past fifty 


\section{ANTIBACTERIAL AGENTS}

years, and tremendous advances are being made every year. The spotlight has been turned on a field in medicine that was long very dark. There are unlimited opportunities in medicine and in science for improving the lot of mankind. 


\section{Index}

The Index does not include items in the alphabetical table on pp. $27-28$, dealing with the sensitivity of various organisms to streptomycin.

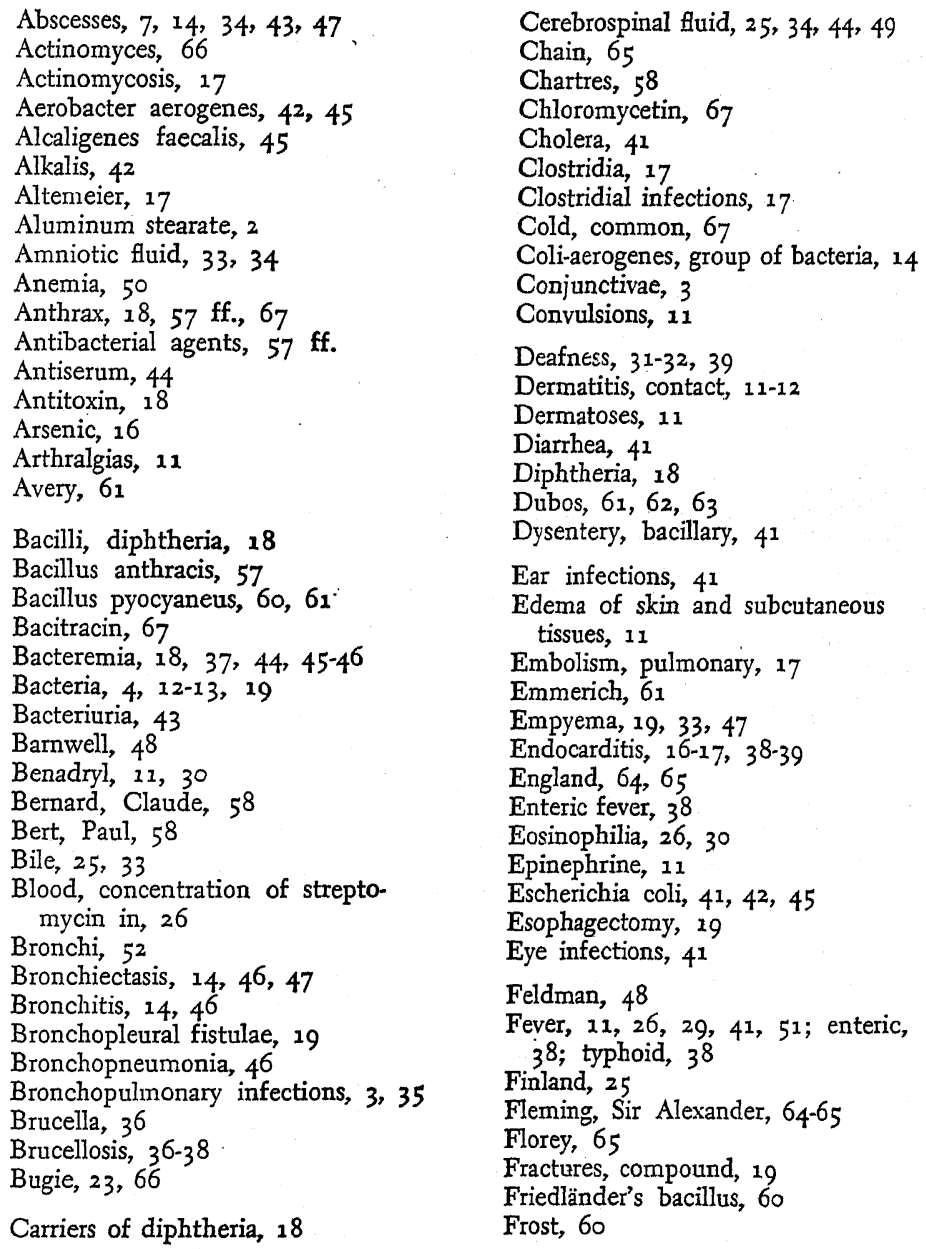




\section{INDEX}

Gastroenteritis, 38

Gastrointestinal tract, 25, 32, 35

Gonococci, resistance to penicillin, 12

Gonococcic infections, 9

Gonorrhea, 9, 18

Heart failure, 17

Hemophilus influenzae, $44,45,46$

Hinshaw, 48

Histamine, 29

Howes, $4^{\circ}$

Hunter, 38, 39

Hypopharynx, 52

Infections, gonococcic, 9; hemolytic streptococcic, 9, and streptococcic, 2, 9; pulmonary, 15-16

Influenza, 67

Intestine, tuberculosis of, 53; streptomycin before operations on, 54

Johnstone, 24

Joints, pain in, 11

Julliard, 58

Kidneys, 25, 34

Klebsiella pneumoniae, 14, 45, 46-47

Koch, Robert, 58

Larynx, 52

Leplat, 58

Lobectomy, 19

Low, 61

Lung abscess, 14, 47

McDermott, 30, 31, 48

Mastoiditis, 18

Mayo clinic, 48

Meningitis, penicillin in, 13-14; streptomycin in, 32, 35; Hemophilus influenzae, 44; gram-negative bacilli causing, 45; with acute miliary tuberculosis, $49-51$

Meningococcus, 66

Metchnikoff, Elie, 59-60

Murray, 25

National Research Council, 65

Nausea, 32

Necrosis, 51

Neurologic disturbances, 26, 30-32, 39

New Jersey, 63
Ocular fluid, 33,34

Office of Scientific Research and Development, 65

Ophthalmic ointments, 11

Osteomyelitis, 18

Otitis media, 18

Oxford, 65

Pain, 26, 29, 34

Paine, 25

Pasteur, Louis, 58-59

Penicillin, as therapeutic agent, 1; dosage forms, $1 \mathrm{ff}$.; amorphous, $1-2 ; \mathrm{G}, 1-2 ; \mathrm{K}, 12-2$; in oil and wax, 2, 9, 10,12, 15; salts of, 2; parenteral use of, 2,11 ; oral use of, 2-3, 15; aerosol, 3, 12, 24; in ointments, 3 ; nontoxicity of, 4,11 ; in vitro, 4, 5, 6, 7, 12, 17; bacteriostatic and bactericidal effect of, 4 ff.; minimum concentration of, 5 ff., 10; intramuscular injections, 6 ff., 10; time-dose relationships, 8 ff., in aqueous solution, $9,10,12,15$; procaine, 9 , 10, 15; intravenous, 10; in tooth paste, 12 ; crystalline form in physiological saline, 14; for pneumococcic lobar pneumonia, 9; trend of treatment by, 10; types of reaction to, 11-12; sensitization from, 11-12; contact dermatitis from, 11-12; building tolerance of, 12; organisms resistant to, $13 ;$ in treatment of meningitis, $13^{-14}$; in bronchiectasis and chronic bronchitis, 14 ; in pulmonary infections, 15-16; 47-48; in bacterial endocarditis, 16-17; in clostridial infections, 17; in actinomycosis, 17; in anthrax, diphtheria, acute and chronic osteomyelitis, otitis media, and mastoiditis, 18 ; as a prophylactic agent, 18-19; preventive of streptococcic sore throat, 19; combined with streptomycin for topical use, 40; discovery and history of, $64-65$; cost of, 66

Peoria, Illinois, 66

Peritoneum, 33, 53

Peritonitis, 33,39

Philadelphia, 54 


\section{INDEX}

Placenta, 25, 33

Pleura, 53

Pleural fluid, 34

Pneumococcus, 12, 15; in bacterial endocarditis, 16; infections due to, 18; carbohydrate of Type III, 62

Pneumonectomy, 19

Pneumonia, response to pencillin, $15-16 ; 63$

Pneumonitis, 36, 46

poliomyelitis, 67

Procaine, 2, 29

Promine, 48, 50

Prophylactic agent, penicillin as, 18-19; streptomycin as, 54

Proteus morganii, 45

Proteus vulgaris, 42, 45

Pseudomonas aeruginosa, 41, 42, 43, 45,61

Pulmonary infections, penicillin for, 15-16; streptomycin for, $46 \mathrm{ff}$.

Pyelonephritis, after streptomycin, 42-43

Pyocyanase, 61

Pyocyanin, 61

Pyribenzamine, 11

Pyuria, 53

Salmonella choleraesuis, 45

Salmonella infections, 35,38

Schatz, 23, 66

Sepsis, 59

Serum sickness, 11

Shigella infections, 41

Sinuses, 52

Sinusitis, chronic paranasal, 3

Skin, 3; edema of, 11; itching and eruptions, 11, 26, 29-30; grafting, 19

Slough, $4^{\circ}$

Sore throat, streptococcic, 19

Spinal fluid, 7

Spirochetal infection, 14

Sputum, 47, $4^{8}$

Staphylococci, 12, 14, 16, 17, 18, 19

Streptidine, 23

Streptococci, 9, 12, 13, 14, 16, 18, 19,60

Streptococcus faecalis, 42,43

Streptomyces griseus, 23
Streptomycin, with penicillin in bronchial infections, 14; toxicity of, 23; A and B, 23-24; complex and residue, 24; constituents of, 23-24; II, 24; sensitivity of organisms to, 25-26, and Table 1, 27-28; solubility of salts, 25 ; concentration in blood, 26; in vitro, 26,36 , 38 ; side reactions to, $26 \mathrm{ff}$.; neurologic disturbances, 30-32; deafness, 31-32; tinnitus, 32; given subcutaneously, intramuscularly, and intrathecally, 33-35; orally, 35 ; inhalation, 35; in empyema, peritonitis, 33,39 ; in tularemia, $35-36$; in brucellosis, 36-38; effect on bacteremia, $37,45-46$; in typhoid fever, Salmonella infections, bacterial endocarditis, 38-39; wound infections, 39-40; gram-negative bacilli, 40; Shigella infections, cholera, eye and ear infections, 41 ; urinary-tract infections, 41-44; pyelonephritis, 42-43; Hemophilus influenzae and other meningitis, 44$45,49-51$; pulmonary infections, 46 ff.; in chronic bronchiectasis, abscess, empyema, 47-48; tuberculosis, 48 ff., acute miliary tuberculosis, with or without meningitis, 49-51, and progressive pulmonary tuberculosis, 51-52; draining sinuses, 52 ; tuberculosis of the urinary tract, 53; prophylactic agent, 54; isolation of, 66; history of, 66-67

Subarachnoid space, 21,34

Sulfadiazine, $13,14,17,37-38,44$

Sulfamylon, $40^{\circ}$

Sulfonamides, 16, 17, 39, 41, 45

Syphilis, 2, 18

Table 1, 27.28

Thoracotomy, 19

Thromboses, 7

Tinnitus, 32

Tissues, concentration of penicillin in, 7,8

Trachea, 52

Trauma, 46

Troches, 12

Tubercle bacillus, 23 


\section{INDEX}

Tuberculosis, treatment by streptomycin, 48 ff.; acute miliary, 4951; progressive pulmonary, 51-52; of the upper and middle respiratory tract, 52-53; of the urinary tract, 53; of pleura, peritoneum, and intestine, 53

Tularemia, $35-36$

Typhoid fever, 35,38

Ulcers, corneal, 41

Urinary-tract infections, 41-44, 53

Urine, 25, 34, 42, 43
Vertigo, 30, 31

Veterans Administration, 48,50

Vibrio, cholera, 41

Virus infections, 67

Vomiting, 30

Waksman, Selman, 23, 24, 66

Walker, $4^{8}$

Weinstein, 9

Wollstein, East Prussia, 57

Wound infections, $39-40$

Zinitel, 54 